\title{
Measurement and Study on Drying Shrinkage Characteristic of Tobacco Lamina Based on Computer Vision
}

\author{
Wenkui Zhu ${ }^{1}$, Zhaogai Wang ${ }^{2, *}$, Delong $\mathrm{Xu}^{1,3}$, and Jinsong $\mathrm{Du}^{1, *}$ \\ ${ }^{1}$ Zhengzhou Tobacco Research Institute of CNTC, Zhengzhou 450001, China \\ ${ }^{2}$ Institute of Agricultural Products Processing, Henan Academy of Agricultural Sciences, \\ Zhengzhou 450002, China \\ ${ }^{3}$ Jinan Cigarette Factory, Jinan 250104, China \\ \{wkzhu79, dlxu88\}@163.com, \{zgwang1999, djsdxx\}@126.com
}

\begin{abstract}
Accurate evaluation of shrinkage characteristic for tobacco lamina during drying process is important for optimizing tobacco primary process. The present work developed a detection and characterization method of shrinkage characteristic based on computer vision. Effect of types and dimensions of tobacco lamina on the shrinkage characteristic were investigated and shrinkage rate variation at different drying stages was also analyzed by this method. The results show that percentage reduction of area, which is obtained by detecting tobacco lamina area before and after drying, can be used to reflect the shrinkage characteristic of tobacco lamina. RSD of measurement results by this method is less than $6 \%$ under test conditions. Compared with upper tobacco leaf, middle tobacco leaf shows the higher shrinkage rate of $14.3 \%$. Dimensions of tobacco lamina also have significant effect on its shrinkage characteristic. The larger size (up 30mm mesh) tobacco lamina shows a higher shrinkage rate. Shrinkage rate of tobacco lamina is closely related to moisture content variation during drying. The shrinkage of tobacco lamina during drying mainly occurs within the moisture content range of $20 \%$ to $14 \%$.
\end{abstract}

Keywords: measurement, shrinkage characteristic, tobacco lamina, computer vision.

\section{Introduction}

Agricultural products processing widely involve the dehydration of materials by air drying. During drying process, one of the most common physical changes is the shape shrinkage, which is associated with the stresses caused by loss of water and heating in the pore structure of materials. Many literatures have reported drying shrinkage characteristics on various porous plant-based materials, such as vegetable, fruit, seeds and so on [1-7]. Due to the flexible skeleton structure of plant leaf, tobacco leaf as important economic crops is easier to shrinkage during drying in its primary process.

In the tobacco primary process, post-harvest tobacco leaf need to be broken into lamina, and then tobacco lamina is dehydrated by hot air drying. The area distribution

\footnotetext{
* Corresponding authors.
} 
of tobacco lamina after drying is key quality index in tobacco primary processing, while which is directly affected by its shrinkage characteristic during drying. Therefore, accurate evaluation of tobacco lamina shrinkage characteristic is important for optimizing tobacco primary process. Generally, traditional sieving method is used to measure the distribution of tobacco lamina size before and after drying, then the difference of twice sieving results could indirectly reflect the drying shrinkage characteristic of tobacco lamina. However, sieving method is difficult to obtain the continuous distribution of tobacco lamina area. At the same time, its accuracy is also affected by tobacco lamina crush during mechanical sieving.

Due to the rapid development of image analysis technology, computer vision system has been more and more applied to the quality detection and classification of post-harvest agricultural products [8-14]. In the present work, the computer vision method was developed to measure drying shrinkage characteristic of tobacco lamina. And by this method, effect of types and dimensions of tobacco lamina on the shrinkage characteristic were investigated and shrinkage rate variation during drying was also analyzed.

\section{Materials and Methods}

\subsection{Tobacco Leaf Samples}

The experimental materials used in the study included two types of flue cured tobacco lamina (a kind of upper tobacco leaf and a kind of middle tobacco leaf). Before experiment, moisture content of tobacco lamina was adjusted to $22 \%$ (on the wet basis) by adding a calculated amount of distilled water to sample. After adjusting the moisture content, they were put into isothermal and equal humidity equipment for $48 \mathrm{~h}$.

Dry processing of tobacco lamina sample was performed in a constant temperature and humidity oven. The drying air conditions are set at $80^{\circ} \mathrm{C}$ and $30 \% \mathrm{RH}$ and sample is dehydrated from the moisture content $22 \%$ to $8 \%$ according to the actual drying technology in tobacco primary process.

\subsection{Experimental Apparatus}

The Fig. 1 shows the computer vision system designed for characterizing the drying shrinkage of tobacco lamina. The system mainly consists of sample distributing unit, image capture unit and image processing unit. Sample distributing unit uses two belts conveys with different speeds and a vibrating convey to realize the dispersed distribution of tobacco lamina on high speed belt. The vibrating convey is located before the lower speed belt conveys. Image capture unit above the high speed belt is set in a closed cabinet to avoid disturb from external light. The color line-scan digital camera (DALSA, SG-32-02K80) and linear LED light source are used in image capture unit. The camera has the maximum frame rate of $18 \mathrm{KHz}$ and the resolution of 2048 , and the corresponding image precision is up to $0.1 \mathrm{~mm}^{2}$. A computer with image analysis program acts as image processing unit. 


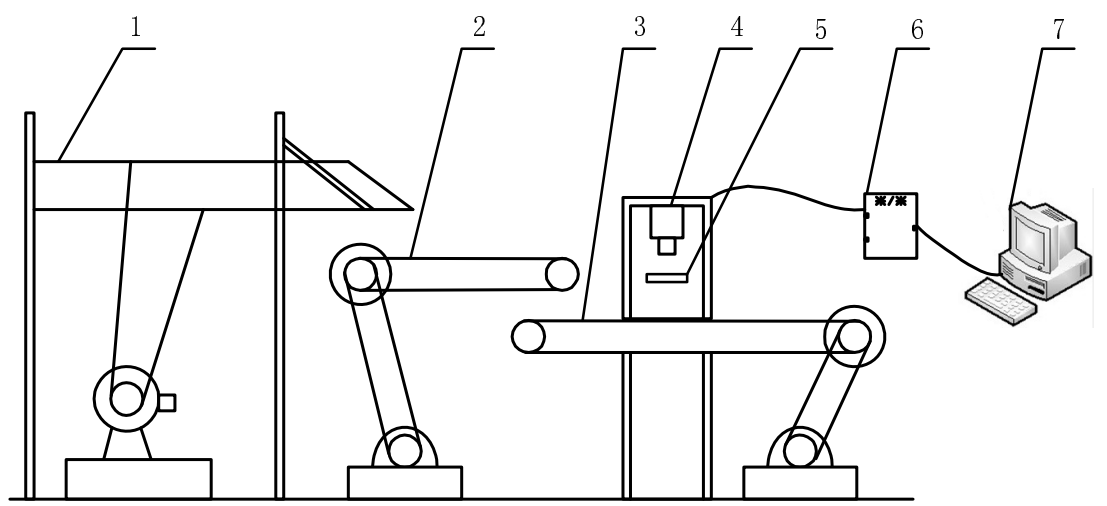

1. Vibrating conveyor, 2. Low speed belt conveyor, 3. High speed belt conveyor, 4. Color line-scan digital camera, 5. Linear LED light source, 6 DA converter, 7. PC

Fig. 1. Diagram of computer vision system

Before the experiment, conveying speeds of two belts conveys are set at $1 \mathrm{~m} / \mathrm{s}$ and $2 \mathrm{~m} / \mathrm{s}$ respectively, and speed of vibrating convey is set at $0.3 \mathrm{~m} / \mathrm{s}$. Tobacco lamina sample is paved on the vibrating convey which will loosen material adequately, and then transported to the low speed belt convey. After the low speed belt conveyor and high speed belt conveyor, the sample is distributed into single layer. The image of tobacco lamina on the high speed belt is continuously detected in real time by image capture unit and then analyzed by image processing unit.

\subsection{Image Processing Methods}

The image of tobacco lamina is collected and pretreated as the flow shown in Fig. 2. Collected color image was firstly transformed as gray level image. After image enhancing, median filter was used to remove the noise, then image binaryzation was carried by choosing proper threshold value. Edge and integrity of tobacco lamina image is close to the actual sample by using Presitt algorithm during boundary detection of image. Fig. 3 shows one of pretreated tobacco lamina image as well as its original image.

Pretreated image was further analyzed to obtain the characteristic values. The image area of each tobacco lamina as key characteristic value was calculated according to the number of image pixels points and area of each pixel point. Then the total area of sample measured can be obtained by summing image area of each tobacco lamina.

\subsection{Evaluation of Shrinkage Characteristic}

Total area of sample before and after drying was detected respectively according to the above image processing methods. The percentage reduction of tobacco lamina area is calculated by the following equation, which can be used to reflect the shrinkage characteristic of tobacco lamina during drying. 




Fig. 2. The flow of image processing

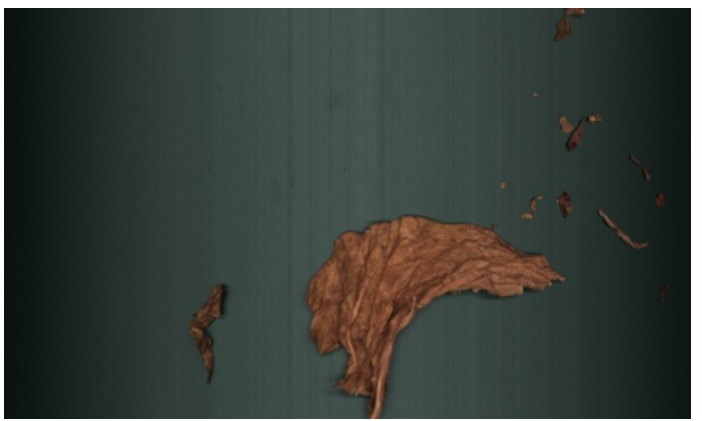

(a) Original image



(b) Pretreated image

Fig. 3. Image of tobacco lamina 


$$
S=1-\frac{A_{1}}{A_{0}}
$$

Where $S$ is the shrinkage rate of tobacco lamina, $A_{1}$ is the total area of sample after drying and $\mathrm{A}_{0}$ is the total area of sample before drying.

\section{Results and Discussion}

\subsection{Accuracy Analysis of Measurement Method}

In order to investigate the method accuracy for shrinkage rate measurement by computer vision, the repeated experiments were carried at different weight levels of sample tested. For each weight levels of tobacco lamina from $50 \mathrm{~g}$ to $400 \mathrm{~g}, 6$ parallel samples were tested respectively to obtain the values of $A_{0}$. After drying, the $A_{1}$ values of each sample were also tested. Table 1 showed the results of repeated experiments.

As can be seen from Table 1, the RSD of sample total area measured before and after drying is less than $2 \%$ for each weight levels of tobacco lamina. When the amount of sample measured is up to $200 \mathrm{~g}$, RSD of $\mathrm{A}_{0}$ and $\mathrm{A}_{1}$ is even less than $1 \%$, which indicates a good reliability of test results for tobacco lamina area measurement by the computer vision system.

Table 1. Repeated experiment at different weight levels of sample

\begin{tabular}{cccccccccccc}
\hline \multirow{2}{*}{$\begin{array}{c}\text { Experiment } \\
\text { No. }\end{array}$} & \multicolumn{2}{c}{$50 \mathrm{~g}$} & \multicolumn{2}{c}{$100 \mathrm{~g}$} & \multicolumn{2}{c}{$200 \mathrm{~g}$} & \multicolumn{2}{c}{$300 \mathrm{~g}$} & \multicolumn{2}{c}{$400 \mathrm{~g}$} \\
\cline { 2 - 10 } & $A_{0}$ & $A_{1}$ & $A_{0}$ & $A_{1}$ & $A_{0}$ & $A_{1}$ & $A_{0}$ & $A_{1}$ & $A_{0}$ & $A_{1}$ \\
\hline 1 & 14.16 & 12.38 & 28.1 & 23.99 & 55.43 & 47.94 & 83.34 & 70.52 & 117.04 & 100.59 \\
2 & 14.1 & 12.53 & 27.89 & 24.33 & 56.2 & 47.54 & 83.13 & 70.63 & 117.51 & 100.88 \\
3 & 14.05 & 12.31 & 28.89 & 23.99 & 56.15 & 47.87 & 82.57 & 70.11 & 117.92 & 100.69 \\
4 & 13.69 & 12.47 & 28.16 & 23.64 & 56.07 & 48.13 & 82.24 & 70.8 & 117.74 & 101.08 \\
5 & 13.89 & 12.48 & 28.18 & 24.14 & 55.67 & 48.09 & 82.24 & 71.15 & 117.26 & 101.02 \\
6 & 14.52 & 12.37 & 27.6 & 24.23 & 55.71 & 48.24 & 82.26 & 71.2 & 117.22 & 101.77 \\
\hline Avg. (dm $\left.{ }^{2}\right)$ & 14.07 & 12.42 & 28.14 & 24.05 & 55.87 & 47.97 & 82.63 & 70.74 & 117.45 & 101.01 \\
SD ( $\left.\mathrm{dm}^{2}\right)$ & 0.28 & 0.08 & 0.43 & 0.24 & 0.31 & 0.30 & 0.49 & 0.41 & 0.34 & 0.42 \\
RSD (\%) & 1.98 & 0.67 & 1.52 & 1.01 & 0.56 & 0.63 & 0.59 & 0.58 & 0.29 & 0.41 \\
\hline
\end{tabular}

Shrinkage rates at different weight levels of sample tested were calculated according to the equation (1). The result is shown in Fig. 4. Standard deviation value of shrinkage rate varied from $0.02 \%$ to $0.005 \%$ with the increasing amount of tobacco lamina tested. When the amount of sample measured is up to $200 \mathrm{~g}$, shrinkage rate reached a stable level of $14 \%$ and its RSD is less than $6 \%$. Considering this results, the sample amount for shrinkage rate measurement of tobacco lamina is choused at the level of $200 \mathrm{~g}$ to ensure a proper measuring accuracy. 


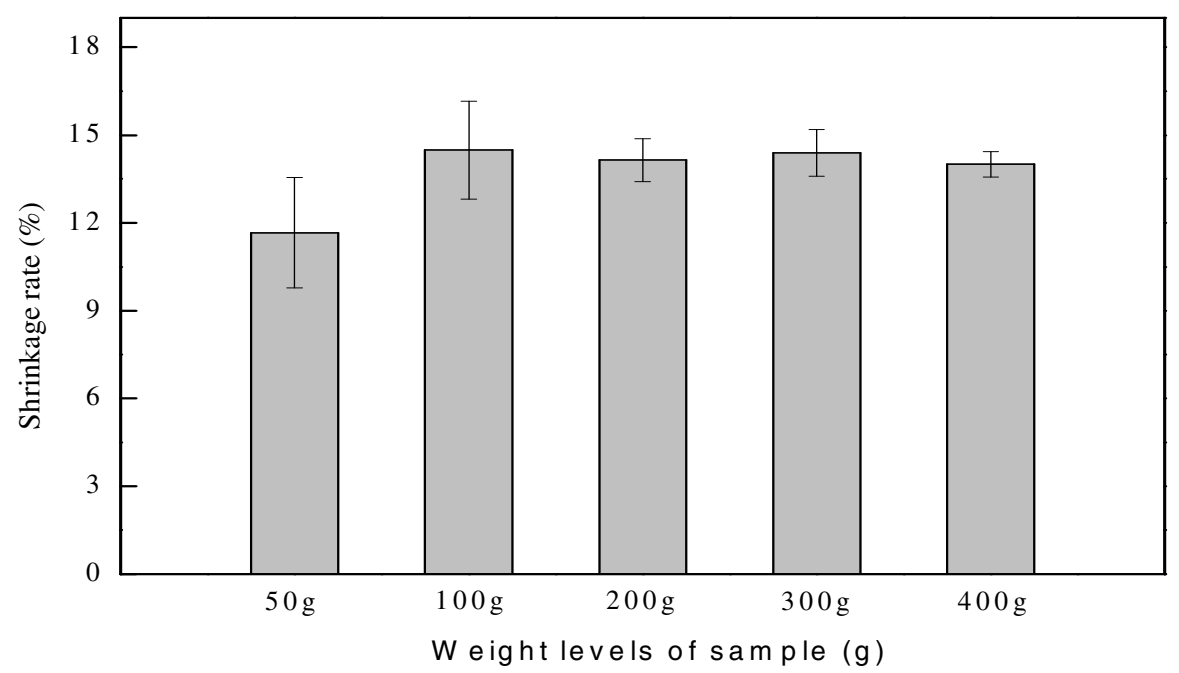

Fig. 4. Shrinkage rate of tobacco lamina at different amount of sample measured

\subsection{Comparison of Shrinkage Characteristic for Different Tobacco Lamina}

Based on the above measurement method, two types of tobacco lamina, including a kind of upper tobacco leaf and a kind of middle tobacco leaf, were analyzed to compare their drying shrinkage characteristic. The result can be seen in Fig. 5. Shrinkage rate of middle tobacco leaf during drying is $14.3 \%$, while that of upper tobacco leaf is $11.9 \%$. Higher shrinkage rate means more significant shrinkage characteristic for middle tobacco leaf during drying, which may be associated with its loose leaf structure than upper tobacco leaf.

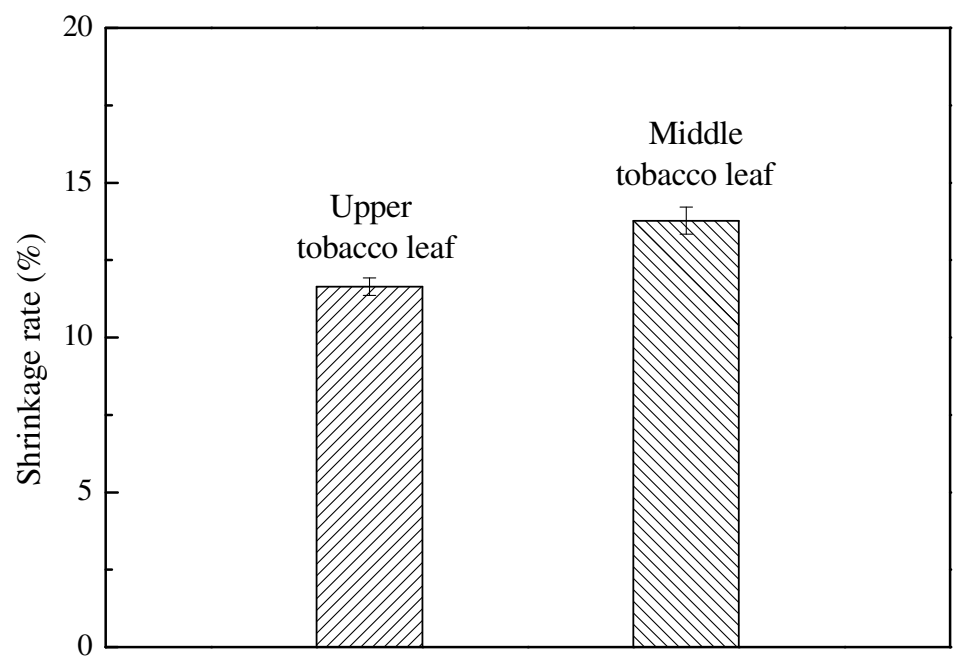

Fig. 5. Comparison of shrinkage rate for middle and upper tobacco lamina 
In order to investigate the effect of different dimensions of tobacco lamina on its shrinkage characteristic, tobacco lamina was sieved into several parts with different dimensions, then area of each parts before and after drying were measured to obtain the shrinkage rate during drying. Table 2 presents the results for upper and middle tobacco leaf at the same drying conditions. It can be seen that the shrinkage rate increased with increasing the dimensions of tobacco lamina, especially for upper tobacco leaf. Shrinkage rate for the part of tobacco lamina under the mesh size of $10 \mathrm{~mm}$ is only $6.44 \%$, while for the part above the mesh size of $30 \mathrm{~mm}$ is up to $13.82 \%$. During drying process, both the internal structure contraction and the curing of leaf surface lead to area shrinkage of tobacco lamina. For the tobacco lamina with larger size, curing and deforming of leaf surface is easier to happen, which will result in more significant shrinkage of tobacco lamina area. This maybe can explain the effect of tobacco lamina dimensions on shrinkage rate.

Table 2. Effect of tobacco lamina dimensions on shrinkage characteristic

\begin{tabular}{ccccccc}
\hline Sample & \multicolumn{3}{c}{ Upper tobacco leaf } & \multicolumn{3}{c}{ Middle tobacco leaf } \\
\cline { 2 - 7 } $\begin{array}{c}\text { Dimensions } \\
\text { mm }\end{array}$ & $A_{0} \mathrm{dm}^{2}$ & $A_{l} \mathrm{dm}^{2}$ & $\mathrm{~S} \%$ & $A_{0} \mathrm{dm}^{2}$ & $A_{l} \mathrm{dm}^{2}$ & $\mathrm{~S} \%$ \\
\hline$<10$ & 46.76 & 43.75 & 6.44 & 43.40 & 38.59 & 11.08 \\
$10-13.2$ & 63.94 & 59.55 & 6.86 & 69.72 & 62.61 & 10.2 \\
$13.2-15$ & 54.22 & 49.20 & 9.26 & 62.76 & 55.98 & 10.8 \\
$15-20$ & 52.42 & 47.98 & 8.47 & 57.97 & 52.97 & 10.06 \\
$20-25$ & 48.92 & 44.21 & 9.63 & 52.21 & 46.69 & 10.57 \\
$25-30$ & 45.16 & 39.32 & 12.93 & 52.52 & 47.14 & 12.6 \\
$>30$ & 46.51 & 40.08 & 13.82 & 52.01 & 45.08 & 13.32 \\
\hline
\end{tabular}

\subsection{Analysis of Shrinkage Rate Variation of Tobacco Lamina during Drying}

Many previous literatures have shown that shrinkage characteristic of materials during drying is closely related with the variations of moisture content at different drying stages [15-18]. The shrinkage rate variation of tobacco lamina with its moisture content was also analyzed in the present work. The area of sample after drying were respectively measured when the moisture content of tobacco lamina decreased to $20 \%$, $17 \%, 14 \% 11 \%$ and $8 \%$, and the shrinkage rates of sample at different drying stages were obtained in Fig. 6.

For both upper and middle tobacco leaf, shrinkage rate of tobacco lamina increased with the decrease of moisture content during drying process. However, there is a more significant varition of shrinkage rate when moisture content of sample at the range of $20 \%$ to $14 \%$. While at the moisture content range of $14 \%$ to $8 \%$, shrinkage rate of sample only showed a little increase. For example, variations of shrinkage rate for middle tobacco leaf is about $6 \%$ when moisture content decreased from $20 \%$ to $14 \%$, but that is only $1.3 \%$ when moisture content continuously decreased from $14 \%$ to $8 \%$. It indicated that the shrinkage of tobacco lamina during drying mainly occurs at the initial drying stage. These results are benefit for optimization of the initial drying conditions to reduce the shrinkage rate of tobacco lamina. 


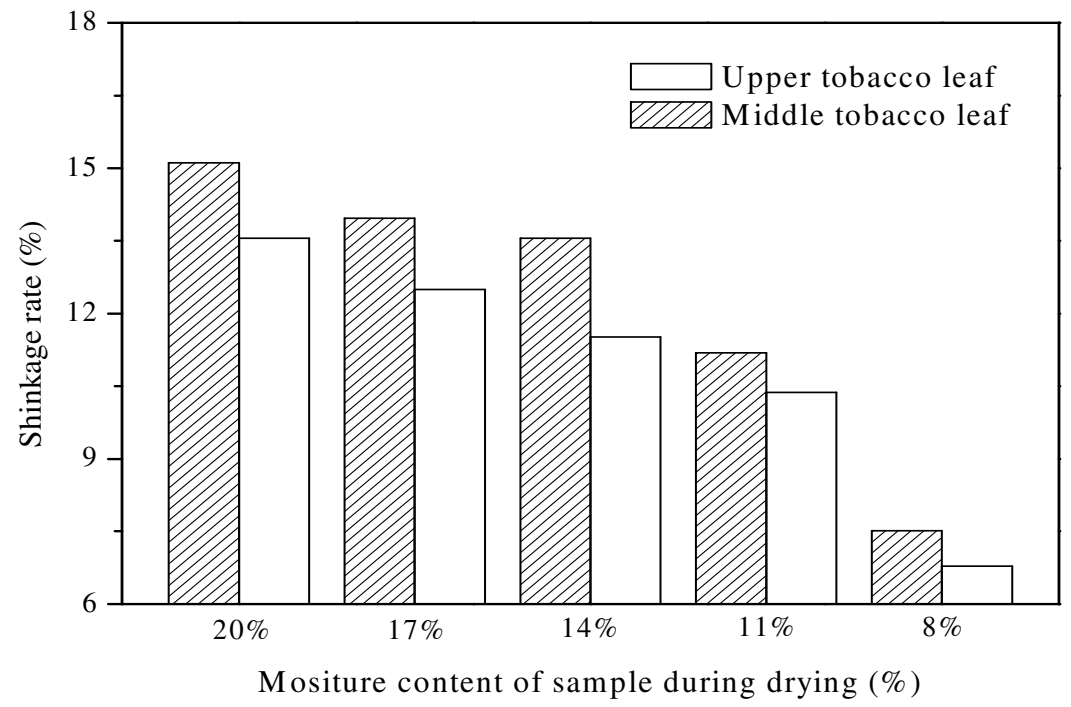

Fig. 6. Shrinkage rate variation of tobacco lamina during drying

\section{Conclusion}

Shrinkage characteristic during drying influences the area distribution of tobacco lamina, which is key quality index in tobacco primary processing. Accurate evaluation of tobacco lamina shrinkage characteristic is important for optimizing tobacco primary process. In the present work, a method based on computer vision was developed to measure drying shrinkage characteristic of tobacco lamina. By this method, effect of types and dimensions of tobacco lamina on the shrinkage characteristic were investigated and shrinkage rate variation of tobacco lamina during drying was also analyzed. The results showed that drying shrinkage characteristic can be reflected by shrinkage rate of tobacco lamina area, as is calculated by detecting the sample area before and after drying. RSD of shrinkage rate measured by this method is less than $6 \%$ under test conditions. Types and dimensions of tobacco lamina have significant effect on its shrinkage characteristic. Middle leaf had a higher shrinkage rate than upper leaf under the same drying conditions. While the larger size (up $30 \mathrm{~mm}$ mesh) tobacco lamina also showed a higher shrinkage. Shrinkage rate of tobacco strips is closely related to moisture content variation during drying. The shrinkage of tobacco lamina during drying mainly occurs at the initial drying stage within the moisture content range of $20 \%$ to $14 \%$.

Acknowledgment. Funds for this research was provided by the National Nature Science Foundation of China Plan Projects (31101373, 51306213). 


\section{References}

1. Mayor, L., Moreira, R., Sereno, A.M.: Shrinkage, density, porosity and shape changes during dehydration of pumpkin (Cucurbita pepo L.) fruits. Journal of Food Engineering 103(1), 29-37 (2011)

2. Agnieszka, N., Adam, F., Alicja, Z.K., et al.: Drying kinetics and quality parameters of pumpkin slices dehydrated using different methods. Journal of Food Engineering 94(1), 14-20 (2009)

3. Mayor, L., Sereno, A.M.: Modeling shrinkage during convective drying of food materials: a review. Journal of Food Engineering 61(3), 373-386 (2004)

4. Cai, L., Shi, M.H.: Experimental study on shrinkage and rehydration of speed during drying process. Journal of Southest University (English Edition) (4), 343-346 (2003)

5. Maskan, M.: Drying, shrinkage and rehydration characteristics of kiwifruits during hot air and microwave drying. Journal of Food Engineering 48(2), 177-182 (2001)

6. Zhu, W.K., Yu, C.F., Li, B.: The Evolution of Moisture, Temperature, Density and Shrinkage Characteristics of Cut Tobacco during Cylinder Drying. In: 65th Tobacco Science Research Conference, USA, Kentucky (2011)

7. Zogzas, N.P., Maroulis, Z.B., Marinos, K.: Shrinkage and porosity of some vegetable during air drying. Drying Technology 12(7), 1653-1666 (1994)

8. Thomas, R., Marco, K.: Robotic harvesting of Gerbera jamesonii based on detection three dimensional modeling of cut flower pedicels. Computers and Electronics in Agriculture 66(1), 85-92 (2009)

9. Fernando, L.G., Gabriela, A.G., Jose, B., et al.: Automatic detection of skin defects in citrus fruits using a multivariate image analysis approach. Computers and Electronics in Agriculture 71(2), 189-197 (2010)

10. Zhang, L.B., Wang, Y., Yang, Q.H.: Kinematics and trajectory planning of a cucumber harvesting robot manipulator. International Journal of Agricultural and Biological Engineering 2(1), 17 (2009)

11. Riquelme, M.T., Barreiro, P., Ruiz-Altisent, M.: Olive classification according to external damage using image analysis. Journal of Food Engineering 87(3), 371-379 (2008)

12. Blasco, J., Cubero, S., Grmez-Sanchis, J.: Development of a machine for the automatic sorting of pomegranate (Punica granatum) arils based on computer vision. Journal of Food Engineering 90(1), 27 (2009)

13. Wan, Y.N.: Kernel handling performance of an automatic grain quality inspection system. Transactions of the ASAE 45(2), 369-377 (2002)

14. Wang, N., Zhang, N., Dowell, F.E.: Determining virtuousness of durum wheat using transmitted and reflected images. Transactions of the ASAE 48(1), 219-222 (2005)

15. Lang, W., Sokhansanj, S.: Bulk volume shrinkage during drying of wheat and canola. Journal of Food Process Engineering 16(4), 305-314 (1993)

16. Gabas, A.L., Menegalli, F.C., Telis-Romero, J.: Effect of chemical pretreatment on the physical properties of dehydrated grapes. Drying Technology 17(6), 1215-1226 (1999)

17. Reza, A., Mohammad, S., Jamal, A.: Evaluation of Concrete Drying Shrinkage Related to Moisture Loss. ACI Materials Journal 110(3), 269-278 (2013)

18. Yadollahinia, A., Latifi, A., Mahdavi, R.: New method for determination of potato slice shrinkage during drying. Computers and Electronics in Agriculture 65(2), 268-274 (2009) 